\title{
Repensando las movilidades en el Archipiélago de Chiloé $^{1}$
}

\author{
Rethinking mobility in the Chiloé Archipelago
}

\author{
Alejandra lazo Corvalán \\ Universidad de Los Lagos, Chile \\ Diego Carvajal Hicks \\ Universidad Católica de Chile, Chile \\ Diego Solsona Cisternas \\ Universidad de Los Lagos, Chile
}

\begin{abstract}
RESUMEN Se presenta en este artículo una propuesta para repensar la movilidad en el Archipiélago de Chiloé desde una perspectiva etnográfica que integra algunas ideas del llamado "enfoque no representacional" para comprender las prácticas de movilidad que ocurren en territorios no metropolitanos. Nos situamos específicamente en geografías espacio-temporales en conexión con el mundo moderno y urbano, pero que se desarrollan en contextos archipelágicos e insulares. A partir de un trabajo de campo llevado a cabo en las islas de este pequeño archipiélago, se comprende la movilidad cotidiana de estos habitantes como un proceso heterogéneo, contingente y ensamblado y por lo mismo, la importancia de repensar distintas formas de acercarse y comprender estas realidades.
\end{abstract}

PALABRAS CLAVE Movilidades archipelágicas; prácticas cotidianas; enfoque no representacional.

\footnotetext{
1. Los autores agradecen a Conicyt (Comisión nacional de investigación científica y tecnológica) por el financiamiento del proyecto Fondecyt de Postdoctorado 3140115. Etnografía de los ensamblajes archipelágicos contemporáneos: movilidades y asociaciones socio- técnicas y naturales en las islas del mar interior de Chiloé (2014-2017).
} 
ABSTRACT This article presents a proposal to rethink mobility in the Chiloé Archipelago from an ethnographic perspective that integrates some ideas of the so-called "non-representational approach" to understand the mobility practices that occur in non-metropolitan territories. We are specifically located in spatio-temporal geographies in connection with the modern and urban world, but that develops in archipelagic and insular realities. From field work on the islands of this small archipelago, the daily mobility of these inhabitants is understood as a heterogeneous, contingent and assembled process and, therefore, the importance of rethinking different ways of approaching and understanding these realities.

KEYWORDS Archipelagic mobilities; daily practices; non-representational approach.

\section{Introducción}

Este artículo busca repensar repertorios metodológicos para capturar de forma más pertinente y cercana las movilidades cotidianas de los habitantes del Archipiélago de Quinchao, en Chiloé. Se relacionan diversos elementos que coexisten con estas movilidades; objetos, cuerpos, paisajes, emociones, etc., que no siempre son considerados por los enfoques tradicionales de los estudios de movilidad. Nos situamos en el archipiélago de Quinchao, sur austral de Chile, territorio configurado por pequeñas islas que dan cuenta de relaciones espacio-temporales que conectan con el mundo moderno y que se caracterizan por lugarizaciones y temporalidades diferentes a la de los espacios urbanos (Lazo y Carvajal, 2017). Desde la movilidad como enfoque (Jirón \& Imilan, 2018), fue posible observar como distintas combinaciones e intermodalidades, en diferentes infraestructuras (Tironi, 2009), desde las lanchas, buses, botes, puentes, ferry, muelles, animales y tecnologías, hasta emociones y sentimientos, jugaban un rol trascendental en la movilidad cotidiana.

El interés por pensar aquello que ocurre en islas y archipiélagos es reciente, y fue planteado principalmente por Baldacchino (2006) en su editorial de apertura del Island Studies Journal. En el año 2011, el tema del archipiélago fue recogido más profundamente por Elaine Stratford, Godfrey Baldacchino, Elizabeth McMahon, Carol Farbotko y Andrew Harwood en su artículo titulado "Envisioning the archipelago".

Sin embargo, los archipiélagos siguen siendo problemáticos en los estudios generales de las islas, y desafían algunas de las dicotomías convencionales en la tradición de los estudios insulares (por ejemplo, mar y tierra, isla y continente, etc.). Al mismo tiempo, estos autores indican que pensar el archipiélago requiere no considerarlo como algo estático, sino por el contrario, pensar en ensamblajes, redes, filamentos, tejidos conectivos, movilidades y multiplicidades (Stratford et al., 2011). 
Nuestra investigación se sitúa en el interés por mirar los archipiélagos a través de la movilidad de sus habitantes, en un tiempo donde las tecnologías y otras materialidades parecen aportar a la movilidad isleña (Baldacchino, 2006). Por lo mismo, es necesario innovar en repertorios metodológicos que contribuyan a capturar las diferentes relaciones y ensamblajes que se originan en las movilidades archipielágicas. Al mismo tiempo, al poner el foco en la experimentalidad y singularidad de la vida cotidiana, es posible entender el territorio en su movilidad transformativa. De igual modo, se ha avanzado en los estudios archipelágicos hacia la comprensión de un nuevo paradigma que enfatiza la constitución dinámica de todas las relaciones sociales a través de la mediación de las movilidades, poniendo en entredicho aquellas concepciones que entienden a los seres humanos como arraigados a lugares fijos (Vannini et al., 2009).

Para el caso que presentaremos a continuación, la movilidad cotidiana se desarrolla y expresa en pequeñas islas periféricas donde se destaca el despoblamiento, la baja interacción inter-islas y con el continente, y una lentitud propia del contexto insular. Es así que la movilidad se entrelaza con momentos como la quietud y la espera ${ }^{2}$, la cual se erige como una variable importante para entender las movilidades cotidianas de los habitantes de las islas de Quinchao. En la espera se organiza, crea e improvisa el próximo viaje, se piensa en el traslado de sus objetos en relación a cada cuerpo y en las distintas combinaciones y lugares del viaje. Los cuerpos isleños poseen ritmos diferenciados según sus movilidades (Bissell, 2009), piensan en las posibilidades de salida o entrada, entre repliegues y aberturas territoriales, a propósito de la lógica de producción y trabajo en Chiloé. Esto se expresa en las maniobras de viaje, en sus fuerzas y formas de abordaje o en cómo se sortean "fricciones" (Vannini, 2011) en superficies inestables y "turbulentas" como el mar (Cresswell, 2010).

La movilidad archipelágica es una experiencia que no se puede reducir, como generalmente se hace, a la relación lineal y pragmática entre el origen y el destino del viaje $^{3}$. En efecto, esta visión tecno-económica busca entender la geografía y la movilidad desde componentes metropolitanos como el flujo y la rapidez que no calzan con una geografía de tipo archipiélago. De esta forma, y apoyados por nuevos enfoques y métodos, sobresalen las discontinuidades del viaje, desde prácticas sensibles y poéticas, considerando las atmósferas afectivas (Anderson, 2009; Bissell, 2009), el clima (Ingold, 2012), los sonidos (Ash \& Simpson, 2016), las dinámicas de espera (Bissell,

2. Como plantea Baldacchino (2003), la identidad de los isleños se manifiesta en su insularidad y lejanía, así como también en el movimiento y en la migración. Para el contexto de este trabajo, la inserción de la industria acuícola en el territorio desde los años 70 (Yáñez, 2011), ha sido la principal fuente de flujos migratorios juveniles en la región (Gobantes, 2011).

3. Sectra (Secretaria planificación de transporte, Gobierno de Chile), "Planes de Transporte urbano, Región de los Lagos”, Chile, 2017. Recuperado de http://www.sectra.gob.cl/planes_transporte_urbano/los_lagos/proyectos_osorno.htm. 
2007; Campos y Aguilar, 2015), las tácticas de subida y bajada, la práctica del caminar (Middleton, 2010) o el dormir (Watts, 2008) que ocurren en el interior de una lancha.

Estas movilidades también están caracterizadas por prácticas asociadas a nuevas tecnologías presentes en las islas. Se observa como en general los objetos tecnológicos, desde su masificación a partir del año 2007 (Bacchiddu, 2012), muestran otras formas de experimentar el territorio y su movilidad. Las tecnologías presentes en cada isla, pueden otorgar la sensación de estar en otro lugar y tiempo, aun cuando simultáneamente, exista el sentimiento de estar aislado e inmóvil. Esto cambia la experiencia de aceleración y ritmo de la vida (Sheller y Urry, 2018), al igual que el "saber viajar" (Jirón e Iturra, 2011) en el territorio isleño. Desde la tecnología, la movilidad adquiere mayor velocidad y "fluidez" (Bauman, 2003). La tecnología juega un papel importante en la potencialidad de vivir acorde con diferentes modelos espacio-temporales, pero resultaría erróneo asignarles toda la responsabilidad a los nuevos modelos de movilidad. Como bien plantea Hiernaux (2005, pp. 7-15), es cierto también que "la tecnología, como sustento de un incremento de la movilidad, es un imaginario profundo que atraviesa las sociedades híper modernas, de tal suerte que se presenta una real demanda en el poder de la tecnología como fuerza liberadora del individuo", a pesar de los constreñimientos que restringen las movilidades.

Tomando en cuenta estos elementos, observamos que la movilidad en el Archipiélago de Quinchao tiene características únicas y particulares que la hacen distinta a las movilidades metropolitanas sobre todo por sus paisajes, sonidos, objetos y materialidades. Se pudo establecer cómo estas movilidades, no sólo son producto de un sujeto, sino que es una experiencia relacional, formada por múltiples elementos, es decir, vivida visceralmente y de una manera heterogénea.

En este contexto, y tomando como punto de partida la necesidad de buscar otras formas para estudiar este tipo de fenómenos con pertinencia territorial, es que hemos construido este artículo como una primera reflexión en torno a enfoques, conceptos y metodologías que permitan aproximarnos a la comprensión de la movilidad cotidiana en este archipiélago.

\section{Aproximación exploratoria a los enfoques no representacionales: conceptos para entender las movilidades}

Teniendo como telón de fondo aquellas investigaciones generadas por lo experiencial, lo personificado y lo fenomenológico es que surgen preguntas sobre cómo las movilidades son objeto y enfoque de investigación (Jirón e Imilan, 2018), lo cual implica un replanteamiento de las ciencias sociales frente a los nuevos desafíos planteados por las movilidades actuales.

En efecto, para esta investigación nos acercamos de manera exploratoria al llamado "enfoque no representacional" el cual entendemos como "una aproximación que 
no busca la validez del dato, sino captar la realidad en su variedad de géneros, saberes y performances" (Vannini, 2012). En un mundo en constante movimiento, este tipo de enfoque se compromete experimentalmente con la diversidad de acciones de la vida cotidiana. Su significación es "no figurativa" y "relacional". Específicamente, se privilegian los entrelazamientos que ocurren entre diferentes actores, humanos y no humanos (Latour, 2005), que co-fabrican el mundo de forma improvisada y sensible, tal como ocurre con la movilidad en este archipiélago.

En definitiva, se trata de cualquier forma comunicativa y sensitiva que dé cuenta de la experiencia de la vida actual, en su condición transversal a los saberes y experiencias que la forman. De ahí que estos enfoques se instalan en un tiempo contemporáneo donde las ideas fijas e inmutables no carecen de sentido, sino más bien, se ponen en tensión en su pragmática y diseño. En rigor, el orden de la representación, se torna crítico e inestable. En este contexto, vamos a pensar no desde el juicio como forma de sentenciar una verdad, sino desde el desplazamiento o lugar performativo de la representación (Thrift, 1986; Vannini, 2012).

Tomando en consideración lo relevante que puede ser el enfoque no representacional para la comprensión de las movilidades archipelágicas, en tanto nos permiten observar el entrelazamiento de los actores que componen la movilidad y el sentido que tiene desde un punto de vista experiencial, es que hemos identificado cuatro conceptos claves: 1) objetos, 2) performatividad, 3) atmósferas afectivas y 4) la espera, como elementos que debieran considerarse en los estudios de las movilidades archipelágicas.

En efecto, uno de los primeros elementos que surge cuando estamos observando las movilidades es que "no nos movemos solos", por el contrario, siempre nos movemos con objetos. Asumiendo que las movilidades en contextos archipelágicos, deben ser capturadas desde una perspectiva hibrida, relacional y ensamblada (Lazo, 2017) es que deben considerarse los objetos o actores no humanos como elementos trascendentales a la hora de explicar las experiencias de los viajes. Según Bissell (2009) los objetos, bolsos, maletas y otras prótesis que se utilizan habitualmente para moverse, deberían ser incorporados en los estudios de movilidad. El desafío epistémicometodológico para las ciencias sociales es identificar como estos elementos o "cosas" pueden constituirse como sujetos apropiados y objetos de investigación social en la actualidad. Observar cómo la gente se mueve con objetos permite pensar que lo que llamamos "social” es materialmente heterogéneo. En esta línea Thrift (1986) reconoce que lo social y lo material se entrelazan, lo que nos invita a observar las movilidades como un todo relacional, en donde están reunidos e interconectados una serie de objetos, tecnologías, cuerpos, etc. La importancia de mirar los objetos radica en el hecho de asumir que, la presencia de estos en los viajes, modifican las situaciones, introduciendo diferencias en las experiencias, por lo tanto los objetos son relevantes a la 
hora de entender la experiencia misma de moverse. Las mediaciones materiales de las movilidades tales como; infraestructuras, teléfonos celulares, bolsas con mercadería, maletas $\mathrm{u}$ otros, pueden orientar a las personas hacia diversas formas de coordinación (Barbier y Trepos, 2011; Latour, 2005; Lazo, 2017). En definitiva, se puede afirmar que las personas "nunca viajan solas", sino que sus pertenencias materiales muchas veces funcionan como verdaderas prótesis o extensiones de sus cuerpos que influyen en la dinámica de sus viajes. Como bien plantea Bissell (2009, p. 190) "correas, manillas pasamanos y ruedas, organizan y condicionan la experiencia de los movimientos". Esto nos convoca a incorporar los atributos físicos de esas materialidades que orientan las movilidades y condicionan la experiencia del viaje.

Un segundo elemento relevante son las performances, pensadas como tácticas y estrategias de movilidad. Como bien plantea Imilán (2017, p. 148) si los discursos nos indican lo que dice la gente, las performances descubren "lo que la gente hace". Para observar de forma pertinente las prácticas de movilidad, es necesario apostar por innovaciones metodológicas en la investigación social que nos permitan descubrir y develar lo que la gente hace en sus movilidades cotidianas. Vannini (2012) afirma que las etnografías no representativas deben observar la performatividad, es decir, centrarse en lo que hacen los actores, en lo que intentan hacer y no hacer. Este enfoque en la acción, por parte de personas y otros actores, enfatiza la importancia de actuaciones ritualizadas, comportamientos habituales y no habituales, los juegos y los diversos guiones que se hacen en la vida cotidiana. Se asume que los organismos, las personas y los objetos tienen capacidad de afectar nuestros mundos, y por ende modifican nuestras tácticas y estrategias para resolver situaciones emergentes. La importancia de considerar las performances, entendidas como las acciones de las personas, guarda relación con que los sujetos son agentes activos en la producción de sus territorios, de los cuales se apropian y re significan en sus movilidades, al mismo tiempo que se van construyendo identitariamente como sujetos a medida que se mueven en contextos particulares. Según Imilán (2017) las performances son creaciones artísticas y dramas sociales a partir de que las personas "ponen en escena" sus cuerpos, los cuales se relacionan con las materialidades (objetos) y terminan constituyendo actos sociales. En esta misma línea, Turner (1988, en Imilán, 2017) afirma que observar los hechos sociales como performances implica indagar en la recreación de los contenidos de una cultura específica. Estas performances se realizan en la vida común de los individuos como prácticas cotidianas, entendidas como "hacer algo de forma repetitiva" (De Certeau, 2011). De acuerdo con lo anterior, y en el caso que describiremos, los habitantes de las islas de Quinchao despliegan performances como formas de habitar sus mundos próximos y acotados, en sus viajes expanden sus cuerpos y conquistan su entorno.

Estudiar la movilidad como performance es poner atención a como los sujetos en el transcurso de sus movilidades articulan diversos elementos (materialidades, emo- 
ciones, normas y otros.) que en su conjunto "hacen a las movilidades" (Imilán, 2017, p. 150). En el caso del Archipiélago de Quinchao, veremos como la performatividad de la movilidad plantea un territorio que se produce o construye de acuerdo a como "se hace la movilidad", de esta forma el territorio es un espacio de carácter contingente, cambiante e inestable.

Finalmente, vale destacar que los sujetos en sus movilidades cotidianas deben crear, improvisar y afrontar diversas coyunturas temporales tales como; sentarse, acomodar el cuerpo, tomar posiciones de descanso, cargar objetos, etc. Todas estas prácticas pueden verse como performances. Sortear las dificultades del clima, pararse, sentarse u otros hechos son también tácticas y estrategias, invenciones situacionales inmediatas que despliegan los sujetos mientras se mueven y que pueden ser registradas por los métodos en movimiento.

Un tercer elemento para destacar son las atmósferas afectivas. Efectivamente, superar la visión reduccionista de que un viaje o experiencia de movilidad debe ser ponderado bajo criterios de uso y funcionalidad, como eficiencia en el tiempo, rapi$\mathrm{dez}$, flujos u otros (Zunino, 2018), implica entender que el viaje es una "experiencia de movilidad", en donde no solamente se conjugan materialidades objetuales y cuerpos, sino en donde también emergen emociones, afecciones y sentimientos, producto del hecho mismo de moverse, de la relación de las personas con las infraestructuras, pero también con el clima, con los paisajes, con los territorios (Ingold, 2012), y con las expectativas y deseos subjetivos propios de las personas. Todo lo anterior, nos invita a pensar los contextos de la movilidad como atmósferas afectivas (Anderson, 2009; Bissell, 2009) es decir, la experiencia de moverse y los modos de transporte como materialidad objetual (en este caso, generalmente lanchas o embarcaciones), propician la emergencia de ciertos afectos y emociones en la experiencia de viaje. Vale destacar que para Anderson (2009) estas atmósferas afectivas son productos de experiencias compartidas en espacios físicos, experiencias que son sensoriales, es decir, las emociones propiciadas en las movilidades se "sienten" corporalmente, he ahí la importancia de considerar los cuerpos en toda su acepción material, física, afectiva y encarnada, como objeto de estudio y categoría de análisis, enfatizando en sus movimientos, performances, estéticas y plasticidades. Registrar lo que las personas van "sintiendo" en el viaje, es uno de los desafíos de los métodos en movimiento, al mismo tiempo que se deba asumir que las características físicas de una embarcación, el clima, los tiempos de demora y espera, etc., pueden eventualmente modificar las emociones o sentimientos que emergen en un viaje.

Conectado con lo anterior, el paisaje juega un rol fundamental en la configuración de estas atmósferas afectivas. Autores como Di Giminiani y Fonck (2015) afirman que el paisaje es determinante de la redefinición que tienen las personas con los espacios, asegurando que: 
"El sentido de pertenencia geográfico se constituye desde la relación entre habitantes y elementos no-humanos del paisaje, dando cuenta de su carácter dinámico. Lejos de ser el paisaje un fenómeno simbólico y discursivo que representa una identidad particular, se trata más bien de un proceso donde los sentidos se configuran a través de relaciones socio-ecológicas" (Di Giminiani y Fonck, 2015, p. 20).

Es justamente a través de estos ensamblajes y vínculos con el mar, embarcadero, viento, lluvia, que los habitantes de Chiloé crean y recrean su cultura a través de la captura sensorial de sus paisajes mientras se mueven. En esta línea, el paisaje es mucho más que un "espectáculo visual", su dimensión poli sensorial a través del cuerpo vivido da cuenta de nuevos modos de aprehensión del paisaje, generando vínculos afectivos e identitarios con los territorios, además de suscitar diversos sentimientos y emociones (Besse, 2010, p. 4).

Un cuarto concepto relevante es la "espera". Esperar es también moverse. Para describir y caracterizar las esperas como factor constituyente de las movilidades es necesario rehuir de la idea tradicional de que la espera es sinónimo de quietud e inmovilidad. Cresswell (2010) plantea que las movilidades deben ser entendidas como una constelación que invita a los investigadores a reconocer también, que las movilidades se planean y se proyectan imaginariamente. La espera debe ser entendida como parte del propio movimiento (Lazo y Carvajal, 2017), aunque a veces es asumida como parte de la lentitud o de la inmovilidad que da paso a los "no lugares" (Auge, 1994). Sin embargo, desde nuestra perspectiva la espera aparece como variante e intensidad del movimiento desde las islas. En la vida en estas islas, la espera no se asemeja a la quietud, sino que implica la articulación del devenir y sus próximos movimientos o viajes. Muchas veces el clima retrasa las salidas, por lo cual se deben esperar días para viajar, siendo estas esperas una afección natural que establece una multiplicidad de formas de moverse. Así, cuando "por motivos de la naturaleza" no se puede salir de la isla, las acciones individuales se vuelcan al presente y al movimiento. Ahora bien, en tiempos en donde la modernidad opera como integración a un mundo siempre negado, el uso de objetos tecnológicos opera como imagen neoliberal del desplazamiento ("puente") al mundo global y económico. Aunque, como sugiere Hiernaux (2005, p. 10), la tecnología juega un papel importante en la potencialidad de vivir acorde con este modelo espacio-temporal. De ahí que es fundamental poder establecer como los sujetos enfrentan estas esperas, e incluso como las construyen imaginariamente, a propósito de las expectativas y deseos presentes en sus intenciones de movilidad.

\section{Explorando metodologías y técnicas para capturar información en movimiento}

Finalmente, creemos que además de un enfoque específico y conceptos claves, es necesario recurrir a técnicas concretas que permitan recoger información en movi- 
miento. En los estudios de movilidad se han utilizado diversas técnicas cualitativas como entrevistas, observaciones participantes, etnografías, introspecciones, investigación archivística, estudios de caso, hasta complementar con experimentos, intervenciones artísticas, performances, fotografías, instalaciones de arte, danza, poesía y video (Sheller y Urry, 2018). No obstante, estimamos pertinente enfatizar principalmente en las técnicas de la etnografía móvil y sus variaciones como el sombreo, además de las entrevistas semi-estructuradas y el registro audiovisual de los viajes.

La etnografía móvil (Jirón, 2011; Novoa, 2015) es una técnica muy pertinente y adecuada dentro de una aproximación no representacional de la movilidad archipelágica. Específicamente, tratamos de "caminar con" y "viajar con", es decir, lograr un "involucramiento co-presente" donde el investigador se mueve con los sujetos empleando la observación y técnicas de registro. Ello implica la "participación mientras se entrevista", en la que el etnógrafo primero participa en patrones de movimiento y luego entrevista personas, ya sea individualmente o en grupos para ver cómo las diversas movilidades son parte de la vida cotidiana. En otras palabras, consideramos que la "etnografía móvil" podría ser una forma de observación participante tradicional, pero en contextos de movilidad actual. Esto significa que el etnógrafo no sólo espera observar lo que está ocurriendo, sino también experimentar, sentir y capturar las texturas, sensaciones, comodidades e incomodidades, placeres y desagrados de una vida en movimiento. Esto significa seguir a los individuos y comprometerse con sus visiones de mundo.

Derivado de la etnografía móvil está el sombreo como técnica esencial para comprender la experiencia del viaje: que sienten los viajeros, como lo experimentan, como organizan sus trayectos, etc. En efecto, ésta técnica implica "el seguimiento de las personas, desde que salen de sus casas hasta que llegan a su destino, es decir, acompañarlas en sus rutinas, observando la forma en que los participantes organizan y experimentan sus viajes, compartiendo y reflexionando colaborativamente sobre su experiencia en movimiento" (Jirón, 2011; Jirón e Iturra, 2011).

En efecto, las etnografías actuales ya no se sitúan en una "comunidad contorneable”, al estilo Malinowsky4 (Delgado, 1999), más bien son parte de espacios actuales, móviles, fragmentados e insulares, como el caso aquí presentado. Jugamos con una observación espontánea o flotante (Pétonnet, 1982) que se va haciendo a cada paso y da forma a territorios siempre nuevos (De Certeau, 1996; Watts y Urry, 2008). De esta manera, vamos estableciendo nuevas pautas de observación y análisis que van transformando críticamente las preconcepciones sobre el estudio o "etnocentrismos" (Velasco y De la Rada, 1997). Podría ser un doble o sombra, pero un doble que siempre acusa variadas lógicas de aproximación y distancia entre la lógica formal y la pragmática de quien investiga, y de quien se mueve de forma cotidiana.

4. Refiriéndose a quien se reconoce como uno de los pioneros en investigación etnográfica. 
Por otra parte, las entrevistas semi-estructuradas funcionan como un complemento subsidiario de los sombreos, a medida que el investigador acompaña a los sujetos en sus viajes, va interrogándolo acerca de lo que siente y como significa lo que hace en el acto de moverse. Este tipo de entrevistas prefigura ejes temáticos que se plantean al entrevistado, lo cual permite que el margen de respuesta se restrinja solo a lo estrictamente necesario para que las personas construyan sus discursos libremente (Baeza, 2002). En definitiva, estas entrevistas nos permiten captar los discursos de las personas, a partir de los cuales ellas articulan relatos en donde se pueden identificar emociones, sentimientos, afecciones y significados relacionados con las experiencias de movilidad.

Por último, los apoyos digitales son muy complementarios para este tipo de investigación pues nos permiten captar sonidos e imágenes a través de videos y grabaciones (Ardèvol, 1998; Orobitg, 2014). La fotografía y el video son un registro realizado en las mismas dinámicas del viaje y del movimiento. Las imágenes le permiten al lector acceder a la realidad de las islas de una forma dinámica, posibilitando no solo su comprensión sobre el fenómeno, sino también otorgando elementos que permitan su propia interpretación de los casos descritos. El uso etnográfico de técnicas de registro y representación visuales y sonoras es explorado en investigaciones recientes con el propósito de dar cuenta de los universos materiales y sensitivos que se imbrican en las prácticas de movilidad (Imilán, 2017) lo que desde nuestra perspectiva se levanta como una evidente innovación metodológica.

Luego de conocer el enfoque, los conceptos y algunas técnicas que nos motivaron en esta investigación, presentaremos extractos de las etnografías móviles realizadas en el embarcadero y las lanchas de Quinchao, junto al "acompañamiento" de algunos isleños que deben salir de su isla por distintos motivos, como forma de "animar" e "invitar" al lector a la movilidad en el archipiélago de Chiloé.

Los habitantes que presentamos en este artículo, residen en las islas de Apiao, Chaulinec y Alao. El primer caso, corresponde a un hombre que vive en la isla de Apiao, trabajador informal y temporero en la ciudad de Puerto Montt. La segunda habitante, es una mujer de la isla de Chaulinec, profesional y religiosa, que habita de forma regular en la isla pero que históricamente, dado su trabajo, ha tenido variadas residencias dentro del país. El tercer caso, es un joven trabajador de Alao, una de las islas más pobres del archipiélago de Quinchao, para quien la movilidad sirve para concretar pagos de servicios, así como para establecer relaciones sociales en espacios urbanos de mayor interés. La conjugación de estas tres formas de viajar, muestran la heterogeneidad de la movilidad y la inmovilidad, en tanto experiencias, cuerpos y materialidades del viaje. 


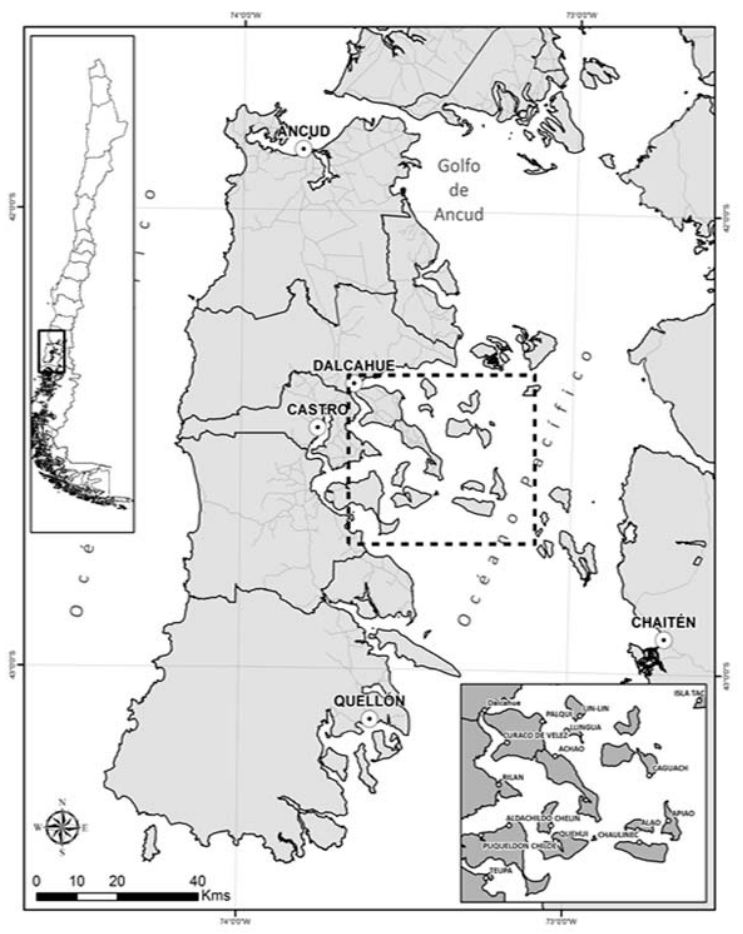

Figura 1. Mapa Quinchao. Fuente: Elaboración propia.

\section{Etnografiando prácticas y atmósferas de la movilidad archipelágica}

Ha pasado media jornada desde que las lanchas llegaron en la fría mañana al pueblo de Achao y ya casi siendo las tres de la tarde, con un cielo que avecina lluvia, todo parece moverse en dirección al muelle para emprender el regreso a las pequeñas islas. Estos movimientos de regreso varían entre las risas, abrazos y las emociones de las despedidas, creándose un tipo de "atmósfera afectiva" en torno al embarcadero (Anderson, 2009; Bissell, 2010). Es posible sentir una especie de desconexión (geográfica), dado que pueden pasar semanas o meses antes de que estas personas provenientes de las diferentes islas puedan volver a verse físicamente. Al mismo tiempo, existe una sensación de agotamiento, o cansancio, puesto que el viaje a la ciudad de Achao, implicó haberse levantado muy temprano y haber estado cumpliendo una jornada intensa de trámites, compras, visitas o trabajo. Además, aparecen las fuerzas desplegadas con las compras y objetos (electrodomésticos, mercadería, ropa, etc.) que ahora se comienzan a trasladar hacia el punto de contacto en el embarcadero. La hora de salida de las lanchas, marca el ritmo de los movimientos y apresura las acciones y estrategias cotidianas. 


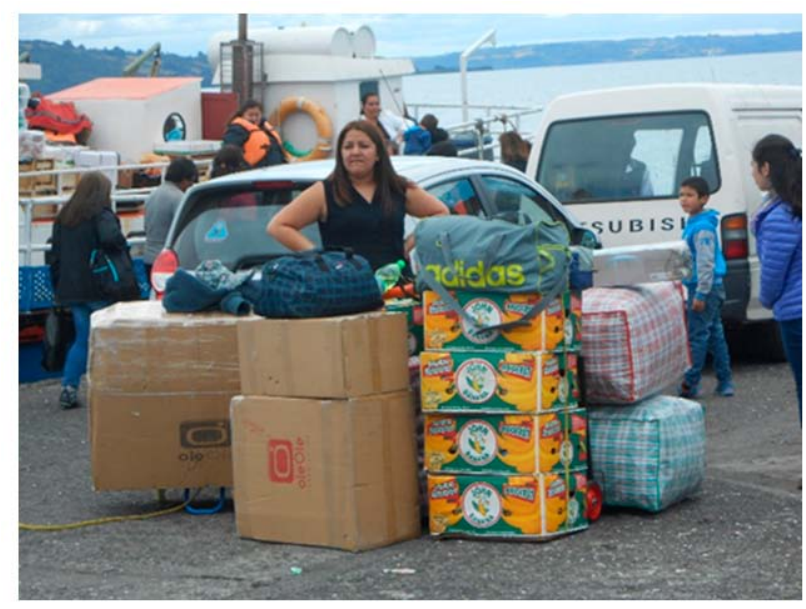

Figura 2. Mujeres en el embarcadero. Foto tomada por los autores.

Algunos jóvenes apuran el paso, y vienen con bolsas de tiendas de centros comerciales desde la ciudad de Castro $^{5}$ (objetos tecnológicos como televisores plasma y parlantes portátiles). Las familias, lideradas por madres e hijos, ayudan con las cargas, y también se observan trabajadores retornando del trabajo con una sola mochila o bolso de mano. La mayoría de las personas traslada sus cosas, a pesar de que hay pequeños carros para llevarlos. Llegando a las lanchas hay que asegurarse de subir los objetos y bolsos primero, para que luego suban las personas. Las cajas y sacos de harina de encargo se instalarán en la parte de arriba, mientras que bolsos como objetos más delicados en un lugar techado para su resguardo. No deja de ser interesante, el hecho de identificar la importancia de los objetos materiales, ya sean estos tecnológicos u otras mercaderías no solo en los viajes, sino en la vida misma de las islas, sobre todo considerando que algunos autores como Stratford et al. (2011) han criticado esta clásica concepción de ver en las islas las cualidades de la tierra y el agua como las que definen estos tipos de territorios, posicionando a las islas como lugares por excelencia "naturales" donde "los valores materiales pierden su influencia". En nuestro caso, se ha podido establecer como estas materialidades son vectores constituyentes de la vida archipelágica en Chiloé.

El pueblo de Achao parece articularse cotidianamente por las llegadas y salidas de las embarcaciones. Será a la hora de llegada de las lanchas (desde las 8:15 a las 10:00 hrs) y luego a la hora del regreso a las islas (15:0o hrs) que el pueblo toma vida y da

5. Capital y ciudad principal del Archipiélago de Chiloé, en el cual está ubicada el complejo de Las 9 Islas de Quinchao. 
inicio a sus funcionalidades y servicios (cajeros automáticos, supermercado, cajas vecinas, "liebres" ${ }^{\circ}$, mercado, comercio, etc.). Achao tiene un carácter intermodal donde se agencian intercambios y valores, desde las islas del interior, hasta el muelle y contextos más urbanos con otros lugares. De este modo, las salidas y desembarcos funcionan como contingencia de un pueblo superpuesto entre los tiempos tradicionales y la transacción neoliberal/urbana, es decir, como un tiempo neoliberal normado (generalizado e impuesto) y un tiempo tradicional, con ritmos más lentos y propios de las dinámicas del territorio, un tiempo "vivido" (Ther, 2012).

Es posible ver en las mañanas mucha gente, pero también, automóviles y camionetas que esperan, mientras se comienzan a descargar un sin fin de productos. En este sentido y dependiendo de las estrategias y cuerpos de la movilidad, el tránsito y paso por el muelle puede ser una experiencia restringida y dificultosa ante la habilidad que implica el despliegue y organización, en materialidades y superficies diferentes (marítimas, terrestres, caminatas, muelle, animal, motorizadas). Esto obliga a los habitantes a desarrollar estrategias para sortear las barreras del espacio y poder acceder a la embarcación, muchas veces acomodando los cuerpos, calculando el espacio y siendo cuidadosos con sus pasos, es decir, "poniendo en escena" sus cuerpos, realizando performances que se entrelazan con la presencia de objetos y materialidades formando así una "constelación de la movilidad" (Lazo \& Carvajal, 2017).

En el muelle habitualmente transcurren las esperas, no como tiempos muertos de fijación, estasis o quietud, sino como momentos donde se planea el viaje, se imagina y se representa anticipadamente, improvisando un asiento en alguna escalinata o donde exista un lugar que permita sentarse y dejar las cosas. Para esperar la lancha, el mercado es un buen lugar, ubicado al lado del muelle y atendido principalmente por mujeres y sus hijas en el contexto del aprendizaje de la elaboración de productos en base de lana. El muelle es un lugar cargado de energías, sonoridades y cuerpos que luego de la contingencia de las llegadas, desembarcos y salidas, se va restituyendo otra vez en el ritmo pausado del pueblo y su flujo regular.

Subirse a la lancha no es fácil, y diferentes cuerpos interceptan la lancha de acuerdo a sus posibilidades. Para cuerpos de la tercera edad o "discapacitados", siempre será complejo dado que al no haber ninguna rampa especial para que aborden la lancha, siempre necesitarán de ayuda de otros para subir, se despliegan así las movilidades dependientes. Los niños, que también pueden ayudar, con sus hermanos o familiares (Madres, principalmente), a veces experimentan lanzándose por debajo de los fierros de la lancha para luego subir. En ese contexto, a las mujeres que vienen habitualmente con mucha carga (mercadería para abastecer el hogar), alguien siempre las ayuda (Lazo, 2017) puesto que les cuesta más el abordaje con objetos. Los

6. Pequeños buses que van desde Achao hasta la ciudad de Castro. Se desplazan por calles pavimentadas y por un ferry para cruzar de una isla a otra. 
hombres en cambio, parecen moverse con mayor facilidad y manejar una técnica de subida con una mano: toman la punta de la baranda haciendo fuerza para luego subir todo su cuerpo. Estas acciones muestran desigualdades específicas, entre quienes deben llevar más objetos, cargas (domésticas) y por ende tienen más dificultades para poder viajar (mujeres), y quienes tienen viajes más simples y expeditos sólo llevando una mochila junto a su cuerpo (trabajadores). Esto indica relaciones de poder entre diferentes cuerpos, ligados en este caso, a la inmovilidad, espera y repliegue de las mujeres en las islas en función del cuidado de la casa y los hijos. A diferencia de los hombres que expresan en su movilidad cotidiana, una relación con el espacio de la producción y trabajo individual, más fluida y con menos esperas. Lo que los desliga de preocupaciones de la gestión doméstica del hogar y del traslado de cosas para abastecer sus hogares.

En efecto, las diferentes realidades económicas de cada isla, delinearán también quien podrá moverse y quien no; dado que salir de las islas en las lanchas de recorrido implica, en términos básicos, un capital para comprar pasaje, mercancías, bonos, etc.

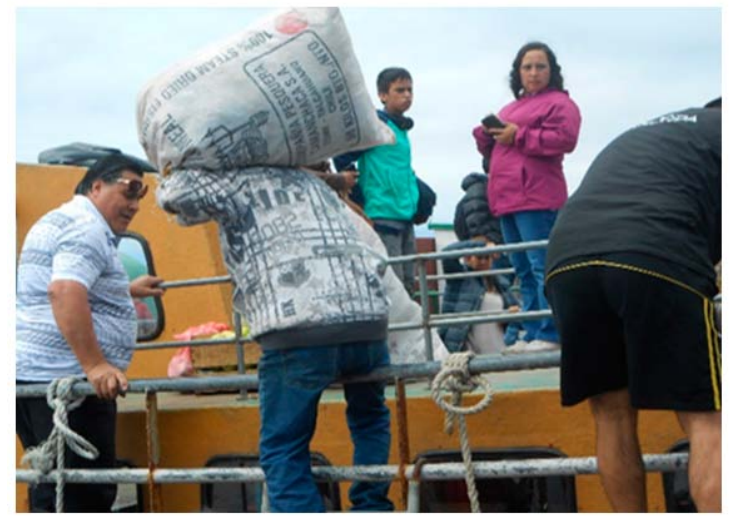

Figura 3. Hombres cargando y subiendo objetos a la lancha. Foto tomada por los autores.

Luego de subirse y dejar todos los bolsos y mercaderías en distintos espacios de la lancha, la gente va tomando posición en las inmediaciones de la lancha. Desde aquí se empiezan a reconocer a los habitantes de cada isla, intercambiando diálogos y conversaciones situadas en la realidad y contexto comunitario de cada isla. El hecho de que los trabajadores y tripulantes de la lancha también residan y sean vecinos de las islas del recorrido, realza lo anterior y hace que no se genere una frontera entre usuario/servicio. Sino que, al contrario, se observa cercanía e interconexión, lo que da cuenta de que mientras la lancha se desplaza, el hábitat, la residencia y el territorio isleño se actualiza dentro de ella. 
Al observar la vida isleña, sus casas, sus interiores y exteriores, se muestra la similitud entre estas y las embarcaciones de viaje cotidiano. Se podría decir que la dinámica de la casa es replicada en la lancha en movimiento. En las cocinas de las casas isleñas normalmente hay fotos de lanchas y recuerdos familiares a propósito de la vida en el mar (mapas, anclas) y también un mueble de madera con amplias cajoneras (aquí se guarda leña, frazadas, entre otros). Curiosamente este último, tiene similitud con el borde de la lancha y el lugar donde habitualmente se sienta la gente para conversar y observar el paisaje. Este mueble-objeto, en la cocina o en la lancha, es escenario de reunión, conversación y proyección, casi una atmósfera afectiva donde no solamente emergen emociones, sino que también se recrea la cultura en clave de prácticas ritualizadas (Imilán, 2017).

En los espacios del interior de la lancha, se siente una intimidad doméstica y cotidiana. Hay bolsas colgadas, hay percheros para poner la ropa y los cuerpos descansan. Aquí, se puede dormir de forma totalmente estirada, tapados, en espacios oscuros y cómodos de la lancha, con colchones y frazadas; hay televisiones, DVD, radios, entre otros elementos.

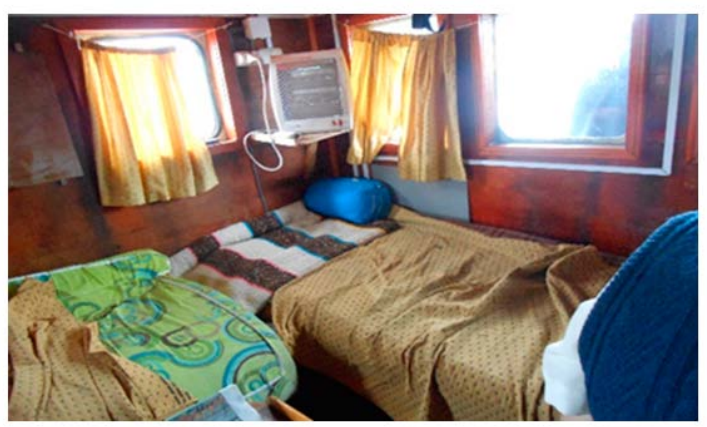

Figura 4. Interior de una lancha. Foto tomadas por los autores.

En la parte exterior de la embarcación habitualmente se ubican los más jóvenes y los trabajadores, a pesar de que el clima no los acompaña por la lluvia y el frio. Se trata de un buen lugar para maniobrar los dispositivos celulares y pasar el tiempo del viaje más rápido, en la simultaneidad espacio-tiempo que ofrecen las tecnologías.

Cuando se viaja al exterior, hay que tener mucho equilibrio y cuidado, el piso está siempre húmedo y la lancha constantemente se va moviendo. Para quien no esté habituado a estos viajes, aquel movimiento puede generar preocupación por una posible caída, lo que obliga a los pasajeros a poner sus cuerpos en posiciones a modo de performances, que les permitan evitar los peligros del viaje. En la parte exterior se experimenta y afecta el cuerpo de distinta forma. Se debe convivir con el frio, la garu- 
$\mathrm{ga}^{7}$ y la humedad en algunos casos. Otras veces, el sol pega fuerte en las caras. Viento, sol, lluvia y el contacto con el mar son parte del paisaje que configura la experiencia de viaje (Ingold, 2012).

En la lancha el cuerpo se acomoda, se prepara para un viaje a casa que puede durar entre una y dos horas. Algunas personas duermen, mientras que otras conversan, cambian de posición, toman aire, se abrigan, toman mate ${ }^{8}$. De todas maneras, se podría decir que una vez que la lancha sale, el cuerpo se va acomodando y buscando un ajuste para el viaje que se aproxima, al momento de la llegada, en cambio, el cuerpo se pone alerta, se prepara.

\section{El viaje con Luis; sombreo y co-presencia de un viaje}

Luis es un hombre joven que no tiene pareja ni hijos. Temprano en la mañana Luis se levanta y se viste rápidamente, se pone un gorro de lana, pantalones y parca para protegerse de los vientos durante el viaje. Es de la zona de Apiao Norte (pequeña isla de Quinchao) y desde muy temprano compartió un mate con su madre, a quien dejaría por varios días, por ir a hacer trámites y por su trabajo en el continente. Luis se demora una hora desde su casa al embarcadero. El camino al muelle es a paso lento, en medio de la oscuridad y guiado por la memoria de los recorridos anteriores. En las islas se camina con linterna, los caminos son de tierra, aunque a veces se puede caminar por la arena. Luis va caminando y debe apurarse para poder llegar a la hora. Corre algunos minutos sobre la tierra para apresurarse, lleva tan solo un bolso de tamaño mediano, como una prótesis incorporada a sus movimientos.

El suelo en la isla de Apiao, entre la tierra y las piedras, es duro y sus caminos tienen cuestas y grandes curvas. Se requiere de fuerza y habilidad para avanzar rápido en el tiempo que se vive intenso cuando hay salidas de lanchas que no esperan. Los isleños están al tanto de los horarios de salida y hacen lo posible por llegar a tiempo. Luego de las salidas, el tiempo de la isla se torna lento y acompasado por los ritmos del ambiente y de la naturaleza.

Ya está amaneciendo, todavía obscuro, llegamos al muelle con Luis y vemos que ya hay una fila que se aproxima lenta y silenciosamente hacia el borde, donde por intermedio de un bote pequeño nos acercaríamos a la lancha. Observamos gente que va a dejar a sus familiares y que ayudan a descargar los objetos que llevarán. Luis está con su bolso y espera tranquilamente su turno de subida.

7. Leve lluvia que cae durante las mañanas en el sur de Chile.

8. La yerba mate en las islas es parte de la organización del habitar de las familias. El mate es un lugar de la mañana en torno al encuentro y organización ante lo que viene en el día o semanas. 
La entrada al bote es compleja y se hace junto a más personas, lo que hace que el equilibrio tenga que ser una maniobra prolija. El pequeño bote nos espera y nos llevaría hasta la lancha, cerca de una escalera donde se debe subir lentamente con bolsos u objetos. Al poner el primer pie en el bote, éste cede un poco hacia un lado, se siente una mayor profundidad y peso de nuestros cuerpos. Es como entrar en una superficie sin centro y que no es firme. En esta acción, es posible afectarse (apoyarse en otro) para no sentirse a la deriva. Es en ese momento cuando uno de los trabajadores de la lancha "Isidora Beatriz", nos hace avanzar por medio de una soga. Luego de esto, Luis impulsa su cuerpo en dirección a la lancha haciendo fuerza principalmente con las piernas, agarra la escalera, sitúa el otro brazo y llega arriba con el impulso. Un movimiento ágil y rápido.

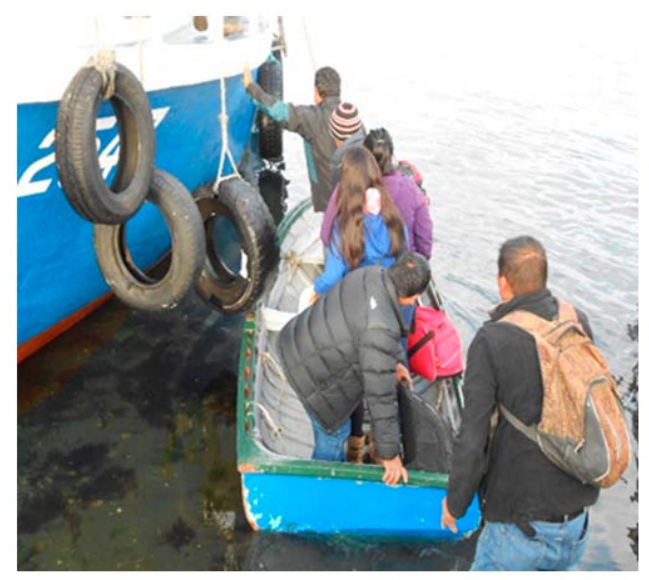

Figura 5. Personas subiéndose a la lancha. Foto tomadas por los autores.

\section{El viaje de Luis: el arraigo y la movilidad por trabajo}

Ya estamos en la lancha, buscamos algún lugar para dejar nuestras mochilas. La lancha ya prendió el motor y lentamente empieza a moverse sin mucho aviso, como quien pasa sin anclarse completamente.

Nos empieza a dar frío y sentimos la humedad de esta mañana. El clima y la maquinación de la lancha es intensa, cuesta mantener una conversación por los ruidos del viaje. Nos ubicamos a un costado de la puerta de bajada al salón subterráneo. Luis nos cuenta el motivo de su viaje de ese día al continente, a la ciudad de Puerto Montt, va a trabajar.

Estamos parados con frio, sin movernos mucho. A pesar de eso, Luis nos habla del mar y de la cultura de pesca artesanal y de río; cultivada y aprendida desde niño en su isla de Apiao. De pronto, nos invita a bajar a los asientos para conversar mejor y más cómodos. Abajo es silencioso y cálido. Como hay espacio, la gente se instala atrave- 
sada en medio de dos asientos e intenta dormir, como performance y estrategia para acomodar un cuerpo que dialoga con las materialidades propias de la embarcación. Al estar ahora sentados, Luis se relaja y se pone cómodo, pone sus piernas muy juntas, como para darse o centralizar el calor.

Luis habitualmente hace este viaje por trabajo, cada quince días o una vez al mes. Viaja siempre sólo y muy pocas veces conversa con alguien. Está acostumbrado a dormir en el trayecto y así optimizar energías corporales para el largo camino que le resta al continente. A pesar de que Luis hace frecuentemente este viaje por motivos laborales, contrario a lo que se podría pensar, no ha querido dejar su isla.

King (2009) refiriéndose a los procesos de migración en la islas, afirma que existen islas marginales que tienden a convertirse en áreas de despoblamiento (en el caso de Quinchao son pequeñas islas con una muy baja densidad demográfica), no obstante, mientras más pequeña y aislada es la isla, más obligados están sus habitantes a abrirse al mercado laboral nacional e incluso mundial, pero sin necesariamente dejar de forma definitiva su lugar de origen y residencia.

Luis se había comprado su primer celular hace poco, un equipo muy básico, de aplicaciones como mensaje de texto, cámara y llamadas. La aplicación de fotografías le llama mucho la atención. Nos pregunta si podemos "meternos" a su celular y buscar en la carpeta de las fotografías. Luego, nos hace elegir una fotografía donde él aparece solo y de esa forma nos señala lo novedoso de la función en torno a una imagen propia. En este sentido, se presume que las tecnologías digitales le permiten, especialmente a las personas jóvenes, "conocer otra realidad". Salir de las islas a través de la virtualidad, de las imágenes y flujos de información simultáneos propios de un presentismo volátil e inestable que parece ser "hiperactualizado". Los jóvenes ocupan también aplicaciones geo-satelitales del celular para poder conocer las rutas de la navegación, el clima y las vías terrestres, por medio de aplicaciones como Waze. Esto da cuenta de un saber situado en torno a las condiciones ambientales y de movilidad isleña. También son usuarios de Facebook, whatsapp y otras redes que sirven para conectarse con otras islas, y con sus familiares, amigos y pareja. Las tecnologías, acortan las distancias desde la propia isla hacia los otros destinos como Achao, Castro y otros lugares del país y el mundo (Lazo, Carvajal y Riquelme, 2020).

Seguimos en el viaje, entre pestañeos y conversaciones, ya casi estamos llegando al pueblo de Achao. La bajada es rápida, ágil y mucho menos complicada que la subida esa mañana en la isla de Apiao. Luis al bajar tiene cuidado con el piso que casi siempre está húmedo. Son casi las diez de la mañana y aún le queda un largo viaje. Nos bajamos, caminamos rápido por calle Serrano, hasta la calle de la biblioteca y Carabineros. Luego giramos hacia la izquierda. Este caminar fue rápido y me decía que volvería a su isla la próxima semana para visitar a su Madre. No hay buses directo a su destino, Luis debe tomar un bus que lo lleve a la ciudad de Castro y luego desde allí tomar un segundo bus directo hasta la ciudad de Puerto Montt. 
El viaje de Luis se da entre una vida construida por apegos familiares en la isla y la optimización de un traslado que resulta largo y periférico, pero necesario para mantener un ritmo laboral, que le permita vivir entre la soledad de su trabajo y su isla. Luis forma parte de muchos hombres jóvenes que no han podido salir ni hacer familia más allá de su isla, que salen esporádicamente por un trabajo que deja algo de dinero para sobrevivir y mantener el apego con una vida isleña cada vez más fragmentada.

\section{El viaje de Gina: el afuera y su isla}

Gina reside en Chaulinec, así como Mirta, su única hermana que queda aún en la isla de un total de siete. Vive en el sector de Capilla Nueva, a un costado del muelle donde llega la lancha desde Achao, en una casa que heredó de su Padre, a quien tuvo que cuidar antes de su muerte. Es religiosa de la congregación filipinos de Castro y además fue profesora de educación básica en el internado de Achao. Tiene 60 años, pero le ha tocado viajar y vivir en otras ciudades de Chile (otras culturas y más redes) a diferencia de su hermana quien nunca ha salido de su isla. Gina tiene relaciones con gente de otras islas de Quinchao, sobre todo contactos frecuentes con las islas vecinas de Alao y Apiao.

A Gina, no le preocupa mucho el tiempo cuando está en su isla, pero si cuando debe ir a hacer trámites a los centros de Achao o Castro. El viaje con nosotros, sería un viaje de regreso, a las 13:45 hrs y viajaríamos en la lancha "Constanza Andrea". Saldríamos desde Achao hacia la isla de Chaulinec (Gina estuvo durante toda esa mañana haciendo trámites en la ciudad de Achao).

Con algo de atraso, cerca de las 14 hrs caminamos rápidamente hacia el muelle (30o mts. aprox.). Ella arrastra su maleta pequeña con ruedas, sobre el camino de tierra, para luego recoger la bolsa que había dejado un poco antes en el muelle. Avanzamos a la lancha, a pesar de su edad su cuerpo se ve energético, distendido y ágil al caminar/moverse en el pueblo. Al subir, Gina mostró técnica y coordinación. Nos subimos rápido y nos ubicamos en la sala de al lado de la cabina, lugar cómodo que incluso tiene cocina, TV, colchones, estufas, lavaplatos. Luego que la lancha partiera, pasado unos minutos, cebamos un mate y lo compartimos con las demás personas que viajaban con nosotros; formándose un ambiente agradable y distendido. Uno cebaba y lo entregaba al compañero o al grupo: esa fue la dinámica durante todo el trayecto. 


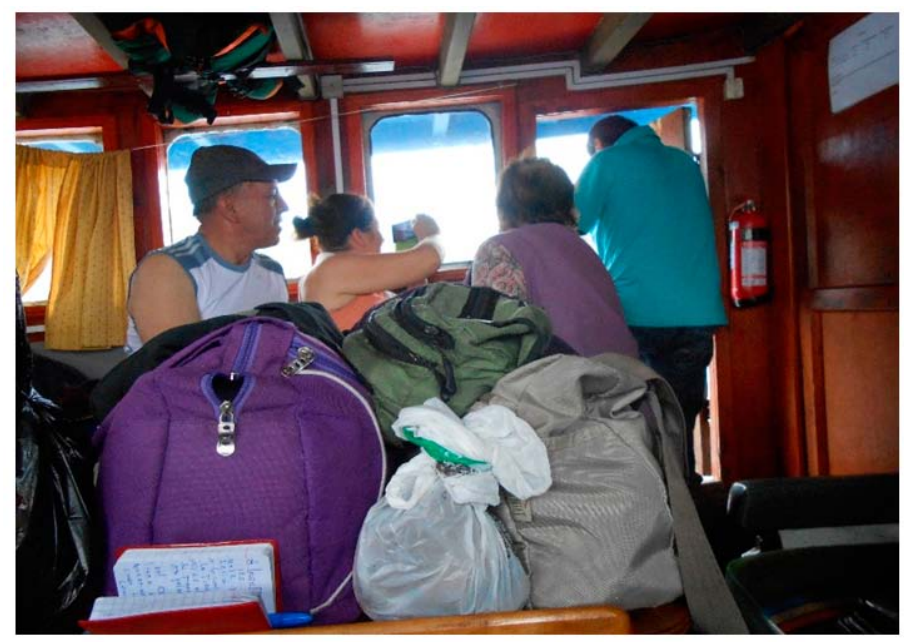

Figura 6. Viaje de Gina. Foto tomadas por los autores.

El interior, donde estamos, es un lugar reducido. Gina, cómoda en un asiento, con el mate en movimiento, aprovecha de ver su celular, de reírse; de hacer reír. Ve sus cosas, sus fotos, Whatsapp y se pone más introspectiva. Va con el cuerpo más comprimido en el asiento. Después del mate, aparece el sueño, producto del relajo con el movimiento del mar.

Conversamos sobre la necesidad de tener siempre estrategias diferentes que se arman en el camino para poder viajar, subir las cosas y tener el tiempo necesario. Es diferente andar haciendo trámites con una serie de objetos, que andar en la isla "con lo propio" (solo su cuerpo, nos dice). Luego nos relajamos, bostezamos juntos, dormitamos y ya estamos casi entrando al Canal de la isla de Chaulinec.

El viaje de Gina podría definirse como una distinción entre el tiempo cotidiano (trámites, visitar amigos, ir de compras) y el tiempo propio del habitar una isla. Ella siempre ha sido móvil, a diferencia de otras mujeres de su isla, su capital social y cultural (a partir de sus estudios de profesora) le permitieron conocer el mundo y establecer redes más allá del archipiélago.

También destacamos las estrategias y creaciones establecidas desde su cuerpo para viajar, así como sus relaciones sociales, las alegrías del encuentro y los objetos, equipajes, mercancías, que hacen de cada viaje una experiencia única.

\section{El viaje con Ariel: buscando la modernidad ausente}

Ariel es de la isla de Alao, una de las islas más precarias del archipiélago de Quinchao. Es del sector de Miraflores, que es una pequeña localidad al interior de la isla, un poco alejada pero donde es posible llegar caminando, en camioneta o caballo. Aquí no hay comercio ni tampoco ningún servicio municipal. 
Como el día anterior, la lancha (La Marbella III) no pudo salir por el clima, Ariel ese mismo día en la noche se comunicó con Carlos para que lo pueda ir a buscar la mañana siguiente en camioneta de "flete" ${ }^{9}$ y así optimizar el recorrido desde su casa (sector Miraflores) hasta el muelle, que implica caminar entre 30 y 40 minutos bajo la oscuridad. Desde esta gestión, Ariel ya estaba empezando la planificación de su viaje. El motivo del viaje, era pagar la cuenta de la luz en Achao y luego, aprovechando, en tanto joven y con libertad de maniobra, ir a Castro a pasar el fin de semana en casa de sus familiares y ver amigos. Ariel a sus 24 años trabaja en Alao, en el rubro de la electricidad y se siente conforme y tranquilo (estabilidad) con este trabajo y la decisión de no migrar ${ }^{10}$ de la isla en donde nació. Le quedan dos años aún de trabajo en la central de Alao.

La lancha saldría ese día a las siete A.M., y Carlos debía (a las seis y cuarto) ir en busca de un primer grupo, llevarlos al muelle, descargar, para luego ir al sector de la casa de Ariel. Desde ahí hasta el muelle, el grupo que viajaba en la camioneta, estaba silencioso. Amanecía, siendo ya casi las siete de la mañana, nos bajamos de la camioneta y caminamos junto a Ariel hacia la lancha. La subida fue rápida, silenciosa, casi siempre individual, sin mucha carga, Ariel llevaba tan sólo una mochila (resistente al agua, al igual que sus zapatos) que dejó al lado del tubo de escape. Nos quedamos en la parte de arriba de la lancha a pesar de que casi todos (personas mayores principalmente) se fueron rápidamente hacia abajo por el frío, y por una garuga que lentamente caía sobre nosotros.

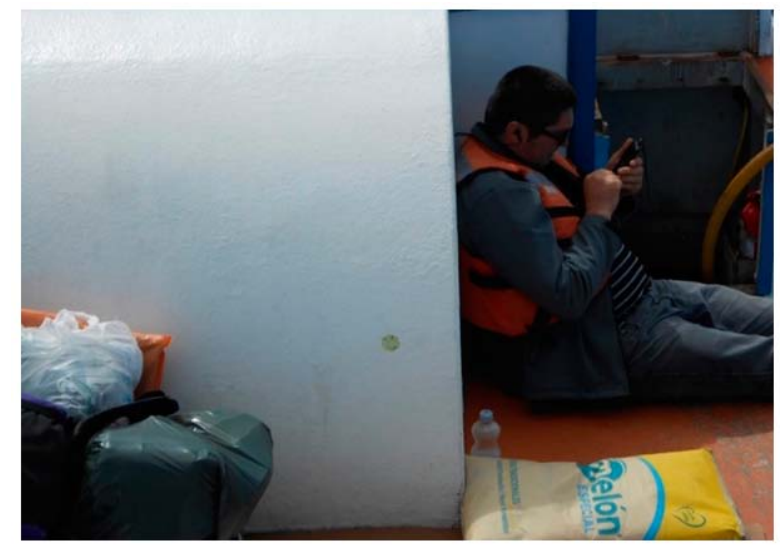

Figura 7. Viaje de Ariel usando su teléfono celular. Foto tomadas por los autores.

9. Vehículos, principalmente camionetas, que van a buscar gente (por 2000 pesos) con necesidades de carga (traslado de objetos pesados), de desplazamiento (Madres con hijos, gente de tercera edad) o por lejanía como en este caso.

10. Movimiento recurrente en los jóvenes de estas islas ante bajas posibilidad de empleo e integración social. 
La garuga a pesar de caer lentamente, se sentía intensa y proseguía junto a nosotros, en las cabezas y caras. Nos pasan rápidamente los chalecos salvavidas naranjos. Éramos tan sólo tres personas las que quedábamos en la parte superior de la embarcación: Ariel, yo, y otro joven de unos 17 años que también viajaba sólo. Él iba con una parca ${ }^{11}$ para la lluvia que traía un gorro, el cual lo protegía y donde podía llevar fácilmente sus audífonos blancos.

El trabajo de Ariel es bien valorado por las personas de su isla. Trabaja en la electricidad: fuente material y simbólica muy importante en los habitantes (sobre todo jóvenes isleños) en relación al centro. Ariel aprovecha de viajar porque con el clima malo, todo es peor, dice. Su voz es baja y casi todo el rato es necesario acercarse un poco más. Ariel mete ambas manos al interior del chaleco salvavidas, lo hace por el espacio central y abierto del chaleco. Esta técnica (objeto y cuerpo), es para el frío y así calentar las manos por un momento, como forma de descanso. Se pone el gorro de la parca, al poco rato se lo saca. El agua ya iba dejando puntos blancos en el cabello y nuestras ropas.

Conversamos en torno a sus formas de comunicación y redes sociales. Me cuenta que ocupa Whatsapp y de esa forma puede mantener con un grado de actualidad, sus relaciones de amistad y los tiempos de espera. Tecnologías que, desde la ausencia del lugar para relacionarse, hacen habitar esa misma virtualidad. Por esta vía, se establecen posibilidades reales de contacto. Muchos de ellos fueron amigos del internado y viven en otras islas, por lo mismo los encuentros no son muy frecuentes.

Siendo las 7:40 A.M., queda una media hora para poder llegar. Seguíamos arriba, y debajo de la lancha ya estaba lleno gente protegiéndose del agua. De pronto, él se mueve para observar hacia abajo, y me invita a que nos pongamos en la escalera. En el segundo escalón, de arriba hacia abajo, y de ese modo evitamos el agua y el frío. Era al costado de la escalera, frente a frente, sin embargo, cuando la gente subía, debíamos movernos un poco hacia atrás.

Entre los que suben y nosotros no hay tensión, al facilitarles un poco más la subida en esa empinada escala. Estando en la escala, requeríamos del apoyo de nuestros brazos, de lo contrario, no podríamos estar sostenidos, nos cansamos. A esta altura la gente empieza a moverse, anticiparse, sabiendo que ya queda poco para llegar a destino.

Bajamos rápidamente. Ariel, camina fuerte y rápido por Serrano, aún no abre el comercio de la ciudad. Él, revisa su celular caminando, cruzamos calle Las Delicias y vamos a la Caja Vecina. El trámite es corto y lo espero afuera, pues el negocio en

11. No tan gruesa, parcas más livianas y ajustadas al cuerpo. Estas nuevas mochilas, son bolsas que hacen con tirantes y que ocupa un lugar más dinámico con el cuerpo, y con el movimiento o viaje. Estas "bolsas mochilas" muy comunes en las ciudades, en su contexto de movilidades y cuerpos que buscan mayor "comodidad" "plasticidad" en torno a los objetos del viaje. 
ese momento, tiene más gente. Tarda unos cinco minutos y luego sale. Nos dirigimos rápido, por calle Ramón Freire, hacia el terminal de buses, que queda a unas cuatro cuadras de donde estamos. Nos despedimos sin decir muchas palabras.

En este recorrido con Ariel, pudimos observar como se mueve con más libertad de maniobra que otros isleños de su edad pudiendo manejar sus tiempos y distancias. Tiene trabajo, un dinero mensual, está tranquilo en su isla. La conectividad es fundamental para éste y muchos otros jóvenes, permitiéndoles conjugar movilidades que lo conectan con redes y personas de otras islas y de ciudades más urbanas, como por ejemplo, éste viaje a Castro.

\section{Conclusiones: Repensando las movilidades archipelágicas}

Uno de los elementos centrales que quisimos destacar en este artículo, es como repensar un mundo en constante movimiento, que en el caso específico de este trabajo, es un contexto rural, aislado y archipelágico. Desde esta perspectiva y al sumergirnos en esta realidad, nos dimos cuenta que si bien, todo proceso de investigación podría ser parcialmente anticipado y planificado por nosotros, la naturaleza generalmente desorganizada, impredecible y fortuita de las realidades empíricas redefinen los términos de la investigación y representación (Marcus, 1998). En este sentido, los ajustes y las redefiniciones fueron claves para buscar una forma de acercamiento, análisis y comunicación de los resultados.

De hecho, fuimos testigos de cómo nuestra propia posición como investigadores influye en el antes, durante y después de la investigación. La elección del diseño, métodos y representación son afectados por cuestiones sociales y políticas, así como también por las visiones en relación a los roles, objetivos y motivaciones de la investigación. Junto a ello, las dificultades siempre estuvieron presentes en el proceso de investigar las experiencias de movilidad cotidiana de habitantes isleños, fue un desafío para pensar de manera diferente y pertinente estas "otras" movilidades. Estudiar la experiencia estando "ahí": viajar con los isleños, compartir su cotidianeidad entre el mar y la tierra, la lancha, el clima y los objetos. En efecto, el trabajo de campo móvil implicó: "viajar con", "estar", "acompañar", "sombrear".

Por otra parte, no debemos olvidar que las prácticas, sujetos y procesos de movilidad estudiados condicionan las elecciones disponibles relacionadas con el objetivo, escala y propósitos de la investigación. Nuestra pregunta central a lo largo de este proceso fue: ¿Cómo pensar y estudiar movilidades no metropolitanas, isleñas y archipelágicas a partir de enfoques y métodos pertinentes?

Creemos que este tipo de investigaciones deben tener como último objetivo comprender las condiciones sociales y culturales de los sujetos móviles, apoyados en estrategias creativas, improvisadas y pertinentemente ajustadas a las realidades siempre contingentes de la movilidad archipelágica. Por lo anterior, nos arriesgamos con un 
primer acercamiento al llamado "enfoque no representacional", identificando conceptos y técnicas, como elementos novedosos para una comprensión más amplia de las territorialidades archipelágicas. Tal como afirma Pugh (2013), estudiar los archipiélagos permite desnaturalizar los espacios a través de los movimientos isleños, los cuales se adaptan y se transforman a partir de recurrentes diálogos entre la cultura, los paisajes, lo material y otros elementos.

Finalmente, creemos necesario contar con ajustes de métodos, procedimientos y conceptos para las necesidades y requerimientos específicos de los temas y proyectos de investigaciones actuales. Es importante reconocer que las innovaciones metodológicas y conceptuales, son llevadas a cabo desde perspectivas externas y que los campos interdisciplinarios podrían ser un buen paso para generar nuevos lenguajes y conocimientos que faciliten el entendimiento de los aspectos emergentes de un mundo cada vez más móvil.

\section{Referencias}

Anderson, Ben (2009). Affective atmospheres. Emotion, Space and Society, 2 (2): 7781. doi: https://doi.org/10.1016/j.emospa.2009.08.005.

Ardévol, Elisenda (1998). Por una antropología de la mirada. Etnografía, representación y construcción de datos audiovisuales. Revista de dialectología y tradiciones populares, 2: 237-249. doi: https://doi.org/10.3989/rdtp.1998.v53.i2.396.

Ash, James y Paul Simpson (2016). Geography and post-phenomenology. Progress in Human Geography, 40 (1): 48-6. doi: https://doi.org/10.1177/0309132514544806.

Auge, Marc (1994). Los no lugares espacios Del anonimato: una antropología de la sobre modernidad. Barcelona: GEDISA.

Bacchiddu, Giovanna (2012). Changing values: Mobile phones and soft drinks in Apiao, Chiloé, Southern Chile. Congreso Internacional de Americanistas. Construyendo diálogos en las américas. Viena, Austria.

Baeza, Manuel (2002). De las metodologías cualitativas en investigación científico social. Diseño y uso de instrumentos en la producción de sentido. Concepción, Chile: Editorial Universidad de Concepción.

Baldacchino, Godfrey (2006). Islands, Island Studies, Island Studies Journal. Island Studies Journal, 1 (1): 3-18. Recuperado de https://www.researchgate.net/publication/26486250_Islands_Island_Studies_Island_Studies_Journal.

Baldacchino, Godfrey (2003). The Coming of Age of Island Studies. Canada: Canada Research Chair in Island Studies. Prince Edward Island: University of Prince Edward Island. 
Barbier, Remi y Trepos Jean-Yves (2011). Humanos y no humanos: un balance de la etapa alcanzada en la sociologia de los colectivos. Trilogia Ciencia, tecnologia y sociedad, 3:123-138. doi: https://doi.org/10.22430/21457778.459.

Bauman, Zygmunt (2003). La modernidad líquida. México: Fondo de cultura económica.

Besse, Jean-Marc (2010). El espacio del paisaje [en línea]. III Jornadas del Doctorado en Geografía, La Plata. Desafíos teóricos y compromiso social en la Argentina de hoy. Recuperado de http://www.memoria.fahce.unlp.edu.ar/trab_eventos/ ev.1488/ev.1488.pdf.

Bissell, David (2010). Mobilities of passagers: emotional atmospheres and sociability of public transport. Environment and planning: Society and space, 2: 270-289. doi: https://doi.org/10.1068/d3909.

Bissell, David (2009). Conceptualising differently-mobile passengers: geographies of everyday encumbrance in the railway station. Social and cultural geography, 10 (2): 173-195. doi: https://doi.org/10.1080/14649360802652137.

Bissell, David (2007). “Animating Suspension: Waiting for Mobilities”. Mobilities, 2 (2): 277-298. doi: https://doi.org/10.1080/17450100701381581.

Campos, Luis y Miguel Ángel Aguilar (2015). L'Expérience corporelle de l'attente dans les déplacements en métro. Sociétés, mobilités, déplacements. Les territoires de l'attente dans les mondes américains d'hier àaujourd'hui, 9: 158-168.

Cresswell, Tim (2010). La política de la turbulencia. En G. Beiguelman y J. La Ferla (comp.). Nomadismos tecnológicos. Dispositivos móviles. Usos masivos y prácticas artísticas, Madrid: Ariel.

De Certeau, Michel (2011). The practice of everyday life. Berkeley: University of California Press.

De Certeau, Michel (1996). La invención de lo cotidiano I, Artes de Hacer. México: Universidad Iberoamericana.

Delgado, Manuel (1999). Observación flotante [en línea]. Recuperado de http://manueldelgadoruiz.blogspot.cl/.

Di Giminiani, Piergiorgio, \& Martín Fonck (2015). El paisaje como proceso de vida: experiencias de domesticación del bosque en el sur de Chile. Revista de geografía Norte Grande, (61), 7-24. Doi: https://dx.doi.org/10.4067/So718-34022015000200002.

Gobantes, Catalina (2011). Migraciones Laborales en un Archipiélago en Transformación. Chiloé ante al Desarrollo de la Salmonicultura. (Tesis para optar al grado de Antropólogo Social), Universidad de Chile, Santiago.

Hiernaux, Daniel (2005) ¿Identidades móviles o movilidad sin identidad? El individuo moderno en transformación. Revista de Geografía Norte Grande, 34: 5-17. 
Imilán, Walter (2017). Performance. En D. Zunino, D. Gucci y P. Jirón (comp.) Términos clave para los estudios de movilidad en América Latina (pp. 147-153). Buenos Aires: Editorial Biblos.

INE (Instituto Nacional de Estadísticas de Chile) (2008), CENSO 2002 Región de los Lagos [en línea]. Recuperado de http://www.ineloslagos.cl/app/bancodatos/bancodatos.htm.

Ingold, Tim (2012). Culture, nature et environnement. Traces, 22: 69-187. doi: https:// doi.org/10.400o/traces.5470.

Jirón, Paola y Imilán Walter (2018). Moviendo los estudios urbanos. La movilidad como objeto de estudio o como enfoque para comprender la ciudad contemporánea. Revista del área de estudios urbanos Quid, 16 (10): 17-36. Recuperado de https:// publicaciones.sociales.uba.ar/index.php/quid16/article/view/2899/pdf_40.

Jirón, Paola y Luis Iturra (2011). Momentos móviles. Los lugares móviles y la nueva construcción del espacio público. Revista Arquitectura del Sur, 39: 44-57.

Jirón, Paola (2011). On becoming the shadow. En: Buscher y otros (comp.), Mobile methods, London: Routledge.

King, Russell (2009). Geography, islands and migration in an era of global mobility. Island Studies Journal, 4(1): 53-84.

Latour, Bruno (2005). Reensamblar lo social. Una introducción a la teoría del actorred. Buenos Aires: Manantial.

Lazo, Alejandra, Diego Carvajal y Hernán Riquelme (2020). Etnografiando (in)movilidades: la tecnología móvil como dimensión del habitar isleño. Etnográfica [En línea]. Recuperado de http://journals.openedition.org/etnografica/7887.

Lazo, Alejandra (2017). Moverse con objetos. En D. Zunino, G. Gucci y P. Jirón(comp.) Términos clave para los estudios de movilidad en América Latina (pp. 105-113). Buenos Aires: Editorial Biblos.

Lazo, Alejandra y Diego Carvajal (2017). La movilidad y el habitar chilote, cambios, rupturas y continuidades en las prácticas de movilidad cotidiana de los habitantes del archipiélago de Chiloé en el sur austral de Chile. Chungara, Revista Antropología Chilena. 50(1): 145-154. Doi: https://doi.org/10.4067/So717-73562018005000203.

Lazo, Alejandra (2017). Las constelaciones de la movilidad y el género en un archipiélago en transformación. El caso de Chiloé en el sur austral de Chile. En: C. Galia y P. Velázquez (comp.), Desigualdad de género y configuraciones espaciales. México: CIEG/PUEC/IG-UNAM/UAM Azcapotzalco.

Marcus, George (1998). Ethnography through Thick and Thin. Princeton: Princeton University Press. 
Middleton, Jennie (2010). Sense and the city. Exploring the embodied geographies of urban walking. Social \& Cultural Geography, 6(1): 107-126. doi: https://doi.org/10 $.1080 / 14649365.2010 .497913$.

Novoa, André (2015). Mobile ethnography: emergence, techniques and its importance to geography. Human geographies, 9(1): 98-107.

Orobitg, Gemma (2014). La fotografía en el trabajo de campo. Palabra e imagen en la investigación etnográfica. QuAderns-e, 19(1): 3-20.

Pétonnet, Colette (1982). L'observation flottante. L'exemple d'un cimetière parisien. L'Homme, 22(4); 37-47. doi: https://doi.org/10.3406/hom.1982.368323.

Pugh, Jonathan (2013). Island movements: thinking with the archipelago. Island Studies Journal, 8(1): 9-24.

SECTRA (Secretaria planificación de transporte, Gobierno de Chile) (2017). Planes de Transporte urbano, Región de los Lagos [en línea]. Recuperado de http://www. sectra.gob.cl/planes_transporte_urbano/los_lagos/proyectos_osorno.htm.

Sheller, Mimi y John Urry (2018). Movilizando el nuevo paradigma de las movilidades. Revista QUID, 16(10): 333-355. Traducción de Javier Serrano.

Stratford, Elaine, Godfrey Baldacchino, Elizabeth McMahon, Carol Farbotko and Andrew Harwood (2011). Envisioning the Archipelago. Island Studies Journal 6(2): 113-130. Recuperado de https://islandstudies.ca/sites/default/files/ISJ-6-2-2011Stratford-et-al.pdf.

Ther Ríos, Francisco (2012). Antropología del territorio. Polis, 11(32): 493-510. doi: https://doi.org/10.4067/So718-65682012000200023.

Thrift, Nigel (1986). Spatial formations. Theory, culture and society, 21(4-5): 41:59. doi: https://doi.org/10.1177/026327640404606o.

Tironi, Manuel (2009). Tecnologías múltiples, infraestructuras líquidas. Sobre la performatividad de una autopista urbana. En M. Tironi y F. Pérez (comp.) Espacios, prácticas y cultura urbana. Santiago de Chile: Ediciones ARQ.

Turner, Victor (1988). The antropology of performance. Nueva York: PAJ.

Vannini, Phillip (2011). Constellations of (in) convenience: disentangling the assemblages of Canada's west coast island mobilities. Social E Cultural Geography, 12 (5): 471-492. doi: https://doi.org/10.1080/14649365.2011.588803.

Vannini, Phillip (2012). Non-Representational Research Methodologie [en línea]. Recuperado de https://www.academia.edu/5217885/Nonrepresentational_Theory_ and_Methodologies_Re-envisioning_Research.

Vannini, Phillip, Godfrey Baldacchino, Lorraine Guay, Stephen Royle \& Phillip Steinberg (2009). Recontinentalizing Canada: Arctic Ice's Liquid Modernity and the Imagining of a Canadian Archipelago. Island Studies Journal, 4, 2: 121-138. 
Velasco, Honorio y Ángel De la Rada (1997). La lógica de la investigación etnográfica. Madrid: Editorial Trotta.

Watts, Laura (2008). The art and craft of train travel. Social E Cultural Geography, 9(6): 711-726. doi: https://doi.org/10.1080/14649360802292520.

Watts, Laura y John Urry (2008). Moving methods, travelling times. Environment and planning D: Society and space, 26(5): 860-874. doi: https://doi.org/10.1068/d6707.

Yáñez, Cristian (2011). De remeros a pasajeros: Memorias de viajes y cambios sociales en una isla. Revista de historia regional y local, 3(6): 231 - 252. doi: https://doi. org/10.15446/historelo.v3n6.23912.

Zunino, Dhan (2018). Ciudades, prácticas y representaciones en movimiento. Notas para un análisis cultural de la movilidad como experiencia urbana. Tempo Social, Revista de sociologia da USP, 30(2): 35-54.

\section{Sobre los autores}

Alejandra lazo Corvalán es Antropóloga, Doctora en Geografía y Planificación Territorial, Université de Toulouse II Le Mirail, Francia, Académica del Departamento de Arquitectura de la Universidad de Los Lagos, Chile. Correo Electrónico: alejandra.lazo@ulagos.cl. iD http://orcid.org/0000-0002-9443-1201

Diego Carvajal Hicks es Sociólogo, Estudiante de Doctorado en Estudios Urbanos Universidad Católica de Chile. Correo Electrónico: diegocarvajalhicks@gmail.com. (iD) https://orcid.org/0000-0002-7092-5397

Diego Solsona Cisternas es Sociólogo, Dr. (c) de Ciencias Sociales en Estudios Territoriales, Universidad de Los Lagos, Chile. Becario ANID, Agencia Nacional de Investigación y desarrollo de Chile. Correo Electrónico: diego.solsona@ulagos.cl. http://orcid.org/0000-0002-7958-1295 


\title{
CUHSO
}

Fundada en 1984, la revista CUHSO es una de las publicaciones periódicas más antiguas en ciencias sociales y humanidades del sur de Chile. Con una periodicidad semestral, recibe todo el año trabajos inéditos de las distintas disciplinas de las ciencias sociales y las humanidades especializadas en el estudio y comprensión de la diversidad sociocultural, especialmente de las sociedades latinoamericanas y sus tensiones producto de la herencia colonial, la modernidad y la globalización. En este sentido, la revista valora tanto el rigor como la pluralidad teórica, epistemológica y metodológica de los trabajos.

\author{
EDITOR \\ Matthias Gloël \\ COORDINADORA EDITORIAL \\ Claudia Campos Letelier \\ CorReCTOR DE ESTILO Y DISEÑADOR \\ Ediciones Silsag \\ Traductor, CORRECTOR LENGUA INGLESA \\ Aurora Sambolin Santiago \\ SITIO WEB \\ cuhso.uct.cl \\ E-MAIL \\ cuhso@uct.cl
}

LICENCIA DE ESTE ARTÍCULO

Creative Commons Atribución Compartir Igual 4.0 Internacional 